\title{
Diaphragmatic rupture resulting from gastrointestinal barotrauma in a scuba diver
}

\author{
J D Hayden, J B Davies, I G Martin
}

\begin{abstract}
A fit young man sustained a ruptured diaphragm during a recreational scuba dive three months after undergoing an uncomplicated laparoscopic Nissen fundoplication for gastro-oesophageal reflux disease. It is proposed that this rare occurrence was attributable to gastrointestinal barotrauma. The injury was treated by laparotomy, mobilisation of herniated abdominal viscera back into the abdomen, repair of the crura and gastropexy. He made a full postoperative recovery. It is concluded that scuba diving should be avoided in patients who have undergone fundoplication.

(Br F Sports Med 1998;32:75-76)
\end{abstract}

Keywords: scuba diving; diaphragmatic rupture; gastrointestinal barotrauma

\section{Case history}

A 36 year old man underwent laparoscopic fundoplication for gastro-oesophageal reflux disease that had failed to respond to medical treatment. ${ }^{1}$ Briefly, the gastrohepatic omentum was divided and the right crus was exposed. A window was created behind the oesophagus to visualise the left crus, which was approximated over to the right and repaired. The fundus was mobilised and brought behind the oesophagus. A short floppy Nissen was fashioned over a 50 French bougie (fig 1). He made an uneventful postoperative recovery and had a good functional outcome, with no symptoms suggestive of "gas bloat".

Three months later, he attended a Professional Association of Diving Instructors introductory scuba dive while on holiday outside the United Kingdom. He had not received a medical examination before the event. A maximum depth of 12 metres was reached during the

Division of Surgery, Centre for Digestive Diseases, The General Infirmary at Leeds, Leeds

J D Hayden

J B Davies

I G Martin

Correspondence to: Dr J D Hayden, Division of Surgery, E Floor, Martin Wing, The General Infirmary at Leeds, Leeds LS1 3EX.

Accepted for publication 22 July 1997

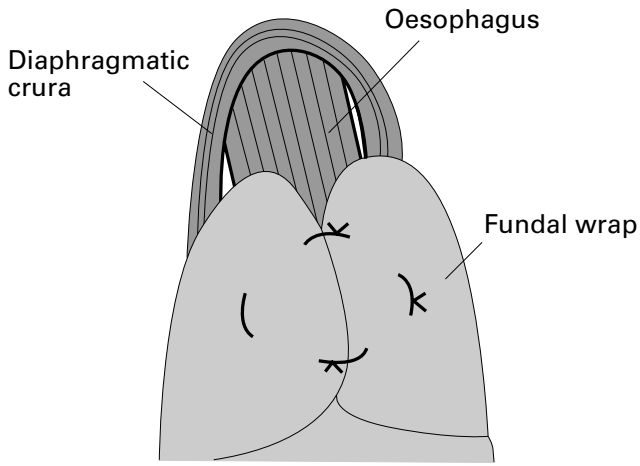

Figure 1 Nissen fundoplication. The fundus of the stomach is wrapped around behind the oesophagus and sutured anteriorly. The crural repair lies behind the oesophagus. dive, with a bottom time of 15 minutes. During routine ascent from this depth, he developed a sudden onset of epigastric discomfort and abdominal distension with tightening of his buoyancy control device (BCD). This was followed by a sensation of tearing in the chest, increasing dyspnoea, and anxiety. These symptoms initially improved at the surface with inhalation of oxygen and removal of his BCD, weight belt, and wet suit. Four days later, he presented to his general practitioner with a history of progressive malaise, anorexia, nausea, and shortness of breath. Examination showed hyper-resonance and reduced air entry in the left lower chest. A plain chest $x$ ray showed bowel shadowing in the left hemithorax (fig 2). A barium meal showed diaphragmatic herniation of $70 \%$ of the stomach into the thorax (fig 3).

Laparotomy showed a diaphragmatic tear at the oesophageal hiatus in the left limb of the right crus and extrusion of at least three quarters of the stomach and most of the transverse colon into the chest. These organs were mobilised back into the abdomen. The previous fundal wrap was found to be still intact. The diaphragmatic defect was closed and a gastropexy was performed. He made an uneventful postoperative recovery and was advised not to scuba dive.

\section{Discussion}

Barotrauma is a tissue injury that results from the failure of a gas filled body space to balance its internal pressure against changes in the environmental pressure. ${ }^{2}$ In scuba diving, pulmonary barotrauma is the most severe form and occurs during ascent when the ambient pressure reduces and airway volumes expand. Failure to release the expanded gas can result in relatively minor injuries, which include mid-

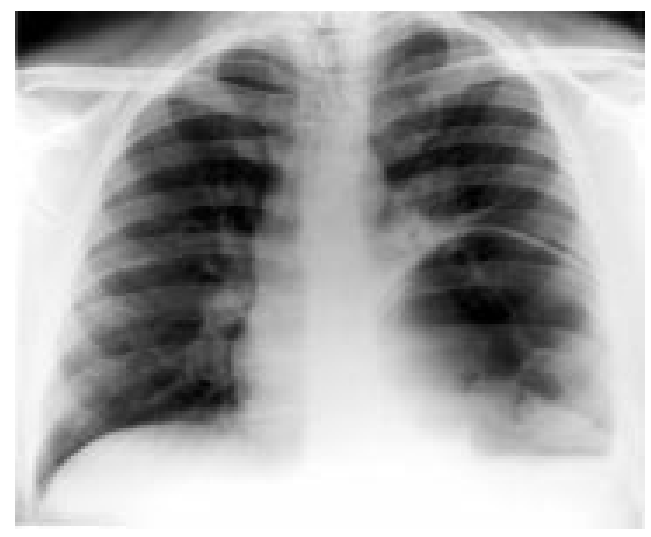

Figure 2 A plain chest $x$ ray showing the abnormal presence of bowel shadowing in the left lower lung field. 


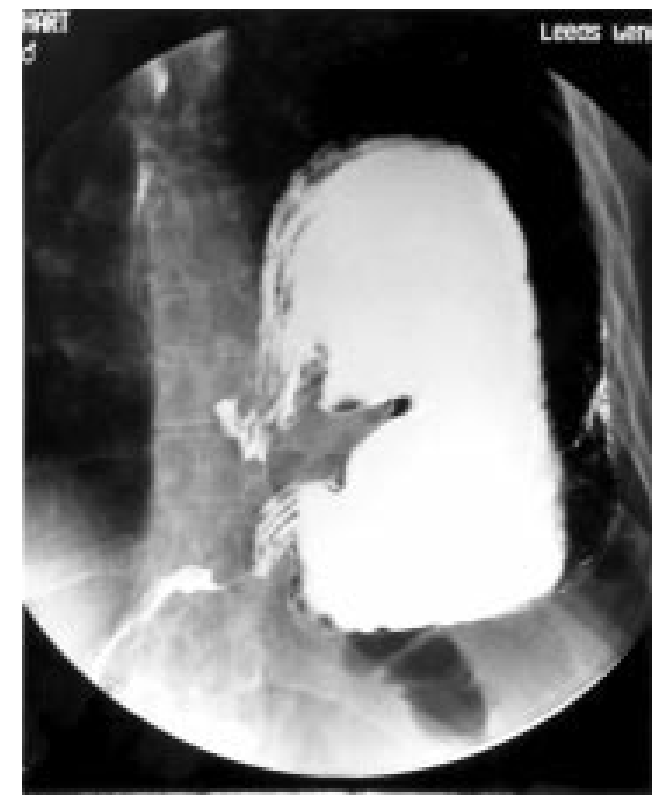

Figure 3 Contrast meal examination showed herniation of $70 \%$ of the stomach into the chest.

dle and inner ear and paranasal air sinus barotrauma or life threatening conditions such as pneumothorax, ruptured pulmonary veins, and air embolism. ${ }^{2}$ Examples of non-pulmonary barotrauma include mask squeeze, ${ }^{3}$ skin barotrauma, and facial baroparesis. ${ }^{4}$ This mechanism of injury does not occur in snorkel divers. In this situation, the airways are initially filled at atmospheric pressure. The subsequent change in barometric pressure is not accompanied by a substantial increase in volume above the total lung capacity.
Diving complications arising as a result of gastrointestinal gas expansion are rare, although rupture of the stomach is reported. ${ }^{5} \mathrm{~A}$ review of the medical literature suggests that this is the first report of a barotraumatic rupture of the diaphragm. We propose that this occurred because of the failure to regurgitate air swallowed at depth during the ascent. It is surprising that the patient was not suffering from "gas bloat" before this injury. ${ }^{6}$

Laparoscopic Nissen fundoplication is a comparatively safe and effective procedure for the management of gastro-oesophageal reflux. ${ }^{1}$ Crural rupture is reported in $1 \%$ of cases, usually in the early postoperative period. ${ }^{1}$ It is vital that patients who have undergone fundoplication seek medical advice before undertaking activities associated with a change in barometric pressure. It must be emphasised that the risk of barotrauma is greatest nearer the surface where a comparatively small change in depth results in a larger change in volume of gas. ${ }^{2}$ We conclude that scuba diving after fundoplication is potentially hazardous and should be avoided.

1 Hinder RA, Filipi CJ, Wetscher G, Neary P, DeMeester TR, Perdikis G. Laparoscopic Nissen fundoplication is an effective treatment for gastroesophageal reflux disease. Ann Surg 1994;220:472-83.

2 Melamed Y, Shupak A, Bitterman H. Medical problems associated with underwater diving. $N$ Engl $f$ Med 1992;326:30-5.

3 Edmonds C, Thomas RL. Medical aspects of diving - part 3. Med F Aust 1972;2: 1300-4.

4 Eidsvik S, Molvaer OI. Facial baroparesis: a report of five cases. Undersea Biomed Res 1985;12:459-63.

5 Molenat FA, Boussuges AH. Rupture of the stomach complicating diving accidents. Undersea Hyperb Med 1995;22: 87-96.

6 Myrvold HE. Laparoscopic antireflux surgery - the merits and problems. Ann Med 1995;27:29-33.

\section{Commentary}

Sport diving is one of the most rapidly growing pastimes. Most doctors have received no formal training in diving medicine and assume, often incorrectly, that the fitness requirements for scuba diving are similar to those for other types of sport. In fact many people have medical conditions that represent a hazard when scuba diving, yet present no risk for participation in sports on land or even swimming. The case described in this report highlights that when considering the fitness of a person to dive it is essential to consider all the physical laws that may operate. In particular we need to be aware of the considerable pressure and volume changes in viscera resulting from a small change in depth when scuba diving.

P WILMSHURST 